\title{
Leveraging National Land and Geospatial Systems for Improved Disaster Resilience
}

\section{Abbas Rajabifard}

Centre for SDIs and Land Administration, The University of Melbourne, Australia

\section{Katie Potts}

Centre for SDIs and Land Administration, The University of Melbourne, Australia

\section{Mika-Petteri Torhonen}

Social, Urban, Rural, and Resilience Global Practice, The World Bank, USA

\section{Federico Barra}

Social, Urban, Rural, and Resilience Global Practice, The World Bank, USA

\section{Ivelisse Justiniano}

Social, Urban, Rural, and Resilience Global Practice, The World Bank, USA

This chapter presents a roadmap for exploring the role of land and geospatial information, the function and responsibility of the institutions that govern the data, and the resulting impact that this data has on the overall resilience of society to disasters.

\subsection{Introduction - Supporting SDGs With Land and Geospatial Information}

National land administration systems and geospatial data infrastructure are fundamental for disaster risk management. They play a key role in facilitating tenure, land use, land valuation and zoning information, for planning, monitoring and implementing responses before, during and after disasters. The input 
of this information enhances resilience capabilities and enables stakeholders to carry out actions required for disaster mitigation and preparedness. With disaster events around the world increasing in frequency and severity, better access to this information is critical to disaster risk management activities.

Achieving the SDGs is parallel with establishing safe and resilient communities that have effective disaster risk management practices in place. Every SDG is related in some way to disaster risk management and requires disaster resilience to some degree. Land and geospatial information is critical to the successful implementation of the SDGs through the provision of reliable land data that provides land tenure security for owners and individuals with interests in land, and for land value, use and development dimensions at the local scale that can guide resilient actions [7]. By addressing the maturity and completeness of land and geospatial systems, and the level of integration into disaster risk management activities, the progress towards establishing a foundation for best practice land management can be understood, and areas for focus can be identified.

This chapter is a resource for enhancing resilience - and in particular, resilience to disaster events in a specific country context by improving the impact of existing land and geospatial systems. It explores the role that land and geospatial systems play within a country, and highlights ways that disaster resilience can be significantly improved for stakeholders, particularly at the community level, through use of existing land and geospatial information and resources. Resilience is the ability of a system, community or society exposed to hazards to resist, absorb, accommodate to, and recover from the effects of a hazard in a timely and efficient manner [9]. In the context of land, land resilience translates to the resilience of land and property and the people to land relationships that exist to recover to the extent that land tenure, value, use and development activities can effectively take place.

\subsection{Addressing Global Problems With Land and Geospa- tial Systems}

National land administration systems and geospatial data infrastructure act as the country's source for recording people to land relationships. The stability of these systems and the security of tenure they provide enables those who have legal rights in land to be confident that those rights can be assured even in the event of a disaster. This security supports wider resilience by providing confidence that if land is physically left - as required by disaster events that demand evacuation, that owners are protected against land grabbing and other activities that would otherwise threaten their right to land.

In addition to providing security to the community, the land records themselves need to be made resilient from any physical impacts that could destroy 
them. It is critical that best practices for data management are adopted to ensure information is digitally recorded and backed up so wider resilience of the community can be supported.

When disasters displace people, land records and geospatial data are key to protecting property rights and building resilience. In 2017, droughts, floods, hurricanes, and other disasters displaced over 18 million people [2]. When people are forced to leave their homes behind, land records offer critical protection of their property rights. This is crucial, since land and homes are usually the main assets that people have. Land and geospatial information are key to ensuring that land records are comprehensive and secure. It informs the what, who, where, how much, and other key attributes of a property. Without this information, it is almost impossible for countries to develop proper disaster response or preparedness plans.

In a disaster situation, comprehensive land and geospatial information and systems can secure the recovery of economic activities by providing accessible and instantaneous data about a disasters impact, value of losses, beneficiaries, as well as the levels of appropriate compensation and investment required to restore activities. In fact, land and geospatial information play an important role in all phases of disaster risk management, namely: disaster prediction (simulation and visualization), prevention, preparedness and mitigation, emergency response, evacuation planning, search and rescue, shelter operations, and post-disaster restoration and monitoring. Moreover, robust land and geospatial systems can help increase resilience by providing detailed and comprehensive information about the earth's surface. This information demonstrates physical hazards with detailed geographical impact areas, as well as tenure and use, and property assets and their values, to guide development of more effective policies, land use planning, and investments.

\subsection{Global Land and Geospatial Systems}

Global land and geospatial systems are important national resources. They contribute to stability and economic growth by providing security and surety around people's greatest assets - land and property. A good land system is made up of an effective land administration system and supported by geospatial information and systems.

When building resilience to disasters, establishing a mature land administration system prior to a disaster event is essential to ensuring a fast and effective recovery. Disasters can result in the loss of official records concerning land ownership, which is why land administration systems are essential to early recovery. They can support tenure security, settlement planning and the transition to sustainable development. Improvements in tenure security and land use practices can foster resilience to disasters through increased food 
security and environmental sustainability. Conversely, the mismanagement of these issues can increase vulnerability to disaster through unsustainable land use and insecurity of tenure [8]. Additionally, secure property rights include the ability for betterment of societal infrastructure, such as road paving, street light installation, and the development of sewerage systems, all of which are made possible through land tax revenue [6]. There also needs to be more institutional collaboration, interoperability and integration at the national level. This needs to happen across the various national data information systems and platforms that exist to support the development and maintenance of geospatial information for improving societal infrastructure [3].

In striving to achieve a mature land administration system that supports resilience to disasters, a number of issues can arise. For example, an inefficient and ineffective land registration process, which can be compounded by an inoperative land information system, an incomplete and/or outdated cadastre, a lack of trained surveyors to conduct high-quality land surveying, and absence of geospatial data sharing protocols. Situations like this contribute to difficulties in tax collection, distort land markets, result in poor urban planning, and also undermine the associated disaster risk management activities.

In cases like this, and in order to improve resilience to disasters, countries should aim for:

- A complete cadastre

- Establishment of effective land and property rights

- Establishment of appropriate land policy

- Restoration of land records

- Development of a legitimate legal framework and adjudication

- Protection of women's land rights

Working towards measures like these can result in positive outcomes, such as:

- Addressing current land and property disputes, evictions and discrimination

- Developing proposed institutional and normative frameworks, including housing, land and property Directorates

- Allocation of land use for temporary purposes (such as shelter)

- Identifying and securing the land records

- Servicing and management of the emergency

- Supplying information to those who have lost their property rights

- Assessing the state of the land records, institutions and problems. 
- Reduction of land disputes

National land and geospatial information can help build disaster resilience. However, we need to better understand the role of such information at the local level, the responsibilities of the institutions that govern land data, and the impact of land and geospatial data on the overall resilience of society.

\subsection{Working Towards the SDGs: Achieving Land Re- silience}

Land is the single greatest resource in most countries, and access to land, security of tenure and land management have significant implications when considering the challenges faced by humanity today. As a finite resource, land - and property, are the main assets of people, and therefore the impact of disruptive events such as disasters, have significant effects on the livelihood of citizens worldwide.

These major disaster events cause large numbers of people to be displaced. Between 2016 and 2017, over 18.8 million people were displaced as a result of disaster events. When disasters displace people, land records and geospatial data are key to protecting their property rights and building resilience.

Disasters are events increasing in frequency and severity and providing countries, worldwide, with an increased impetus to address these events. They are not only having devastating impacts on the world's economies, but, most importantly, on the main assets of their citizens: land and property. In addition to the initial impacts of a disaster, the ongoing and secondary impacts, which can cause major disturbances, need to be considered too. For example, it is often necessary for homes and fields to be abandoned during disasters, however, returning may be restricted due to insecure tenure and the inability to prove prior occupation. Once access to land (a core social safety net) is lost, resuming livelihoods becomes challenging or even impossible, which consequently, increases vulnerability. Families face the prospect of duress selling of assets at reduced prices and moving to informal urban settlements.

There is wide recognition that national land administration systems and spatial data infrastructures are fundamental for disaster risk management. They play a key role in facilitating pre and post disaster tenure, land use, land valuation and zoning information within a unified geospatial platform for planning, monitoring and implementing responses. The input of this information enhances resilience capabilities and enables stakeholders to carry out required mitigation and preparedness actions.

Land and geospatial information can also assist with disaster reduction, risk reduction, preparedness, mitigation and emergency response. It can also expedite recovery operations by providing data on the impact, value of losses, 


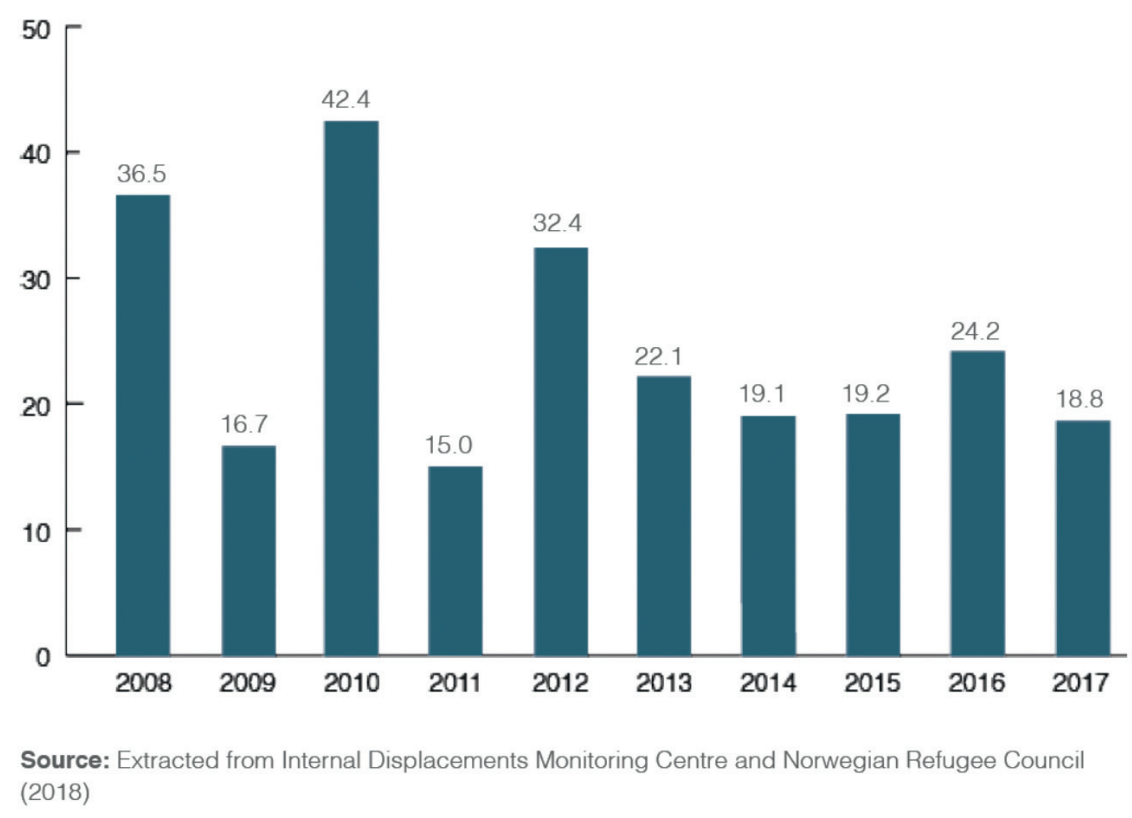

\section{FIGURE 5.1}

New human displacements due to disasters (2008-2017) [2]

and the investment needs for recovery and reconstruction. Better access to information, along with more secure tenure, yields land use and management decisions that take resilience into account and reduce vulnerability, which can result in improved land resilience and overall resilience to disasters.

Sharing this information with disaster risk management agencies and enabling them to harness this valuable data in their planning and operations enhances the overall process and supports government-wide agendas. However, in many contexts, there is a disconnect between a number of these key elements. In order to achieve land resilience, available land and geospatial resources need to be applied and continually improved upon to meet the needs of the community through the application towards disaster risk management activities.

In order to get to this point and achieve land resilience, three critical elements need to be founded within a country: a mature land administration system, comprehensive geospatial data and systems, and established relationships for sharing with disaster risk management agencies.

In addition to having these elements in existence within a country context, the land administration system, geospatial data and systems need to also be physically resilient to disaster. In contexts where land administration is primarily paper based on not digitally recorded a large vulnerability is present. 


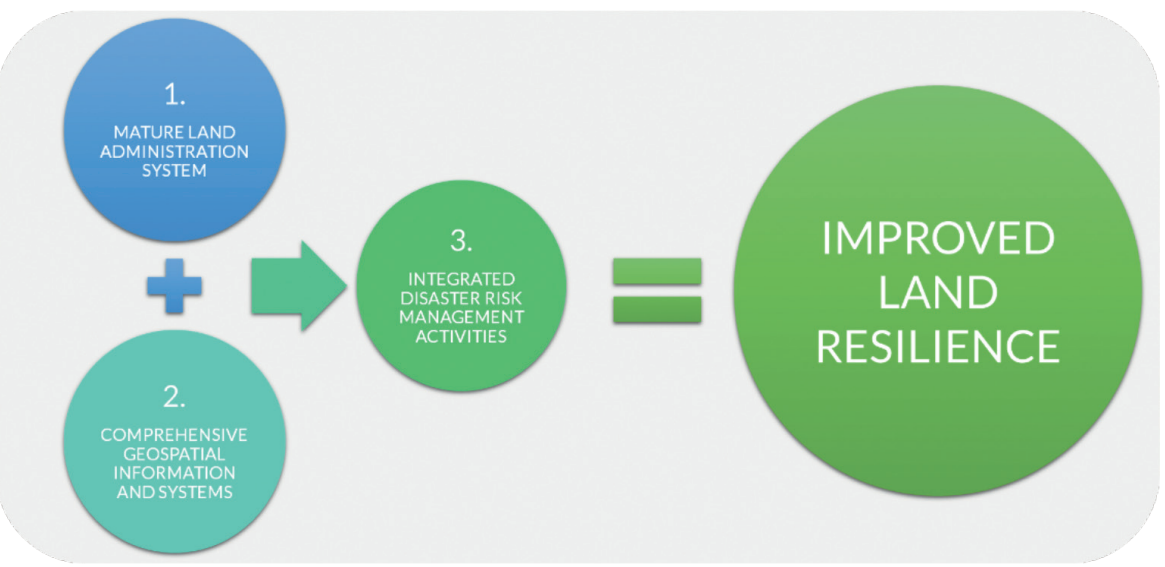

\section{FIGURE 5.2}

Key elements for improved land resilience

Equally, geospatial data and systems that are not adequately maintained or backed up are not resilient to an event that may impact its physical location. Securing both the information itself to make it resilient and leveraging the information to support resilience activities are key priorities.

\subsection{Global Development Frameworks}

Several key initiatives aiming to build resilience to disasters have emerged around the world in recent years. Many of these initiatives tackle a broad range of issues at a number of levels ranging from global or national down to local and community levels. In particular, the 2030 Agenda for Sustainable Development, the Hyogo Framework for Action, and the Sendai Framework for Disaster Risk Reduction aim to substantially reduce the risk of disaster and losses through the implementation of strategic goals and integrated and inclusive measures that prevent and reduce hazard exposure and vulnerability to disaster, increase preparedness for response and recovery, and thus strengthen resilience. They also outline key points that relate to improving resilience to disasters, as well as highlighting the positive effects that national land and geospatial systems can have. In addition, the Integrated Geospatial Information Framework [3] builds on many of these ideas with a focus on geospatial information and how it can be improved to support global development.

The 2030 Agenda for Sustainable Development outlines a need for new data acquisition and integration approaches, including supporting developing countries to strengthen the capacity of their national data systems to ensure 
access to high quality, timely, reliable and disaggregated data [5]. The report identifies a series of goals and indicators to assess and measure the progress of development in these areas. This includes national land and geospatial information, and the application of this data to address the identified sustainable development goals (SDGs).

The Hyogo Framework for Action and the Sendai Framework for Disaster Risk Reduction both respond to global issues around disaster risk management, improved resilience and sustainable development. The Hyogo Framework for Action underscores the need for, and identifies ways of, building the resilience of nations and communities to disasters. Sustainable development, poverty reduction, good governance and disaster risk reduction are identified as mutually supportive objectives. It puts forward that in order to meet the challenges ahead, there must be accelerated efforts to build the necessary capacities at the community and national levels to manage and reduce risk [9]. Further to this, within the Hyogo Framework for Action, land issues were established as one of the key priorities for the period of 2005-2015, and have been gaining momentum within the disaster risk management community in recent years.

The Sendai Framework for Disaster Risk Reduction follows on from the Hyogo Framework for Action. It aims to substantially reduce the risk of disaster and losses in lives, livelihoods and health and in the economic, physical, social, cultural and environmental assets of people, businesses, communities and countries. It works to achieve this through the implementation of integrated and inclusive measures that prevent and reduce hazard exposure and vulnerability to disaster, increase preparedness for response and recovery, and thus strengthen resilience [4]. The Framework has identified seven global targets which address areas, including: global disaster mortality; number of people affected by disaster; direct disaster economic loss; damage to critical infrastructure and disruption to basic services; creation and implementation of disaster risk reduction strategies; international cooperation; and availability and access to multi-hazard early warning systems and disaster risk information and assessments. Learning from the experience of implementing the Hyogo Framework, the Sendai Framework has identified four areas requiring further focused action within and across sectors by States at local, national, regional and global levels. These four areas are:

1. Understanding disaster risk: comprehending all the dimensions of vulnerability, capacity, exposure of persons and assets, hazard characteristics and the environment so that the knowledge can be used to inform risk assessment, prevention, mitigation, preparedness and response.

2. Strengthening disaster risk governance to manage disaster risk: Fostering collaboration and partnership at national, regional and global levels.

3. Investing in disaster risk reduction for resilience: Essential investments to enhance people, communities and the environment. 
4. Enhancing disaster preparedness for effective response and to 'Build Back Better' in recovery, rehabilitation and reconstruction: taking the opportunity to strengthen and enhance all phases of disaster risk management

The overall focus is to prevent new disasters and reduce the existing disaster risk through the application of prevention and reduction measures to economic, structural, legal, social, health, cultural, educational, environmental, technological, political and institutional areas. To achieve this effectively, enhanced implementation capacity, and strong country commitment that is facilitated through political leadership is required.

In addition to the above frameworks, the Integrated Geospatial Information Framework released in 2018 by the United Nations and the World Bank complements the above agendas, which unequivocally call for globally coordinated actions in new data acquisition and integration approaches [3]. The vision and mission of the IGIF is to address the SDGs and note that strategies and frameworks around the use and management of geospatial information will be required to realize some of these goals, and within the context of disaster risk management, geospatial information will play an important role in developing policies, strategies and legislative arrangements to future challenges faced.

The purpose of the IGIF is to guide the development and strengthening of geospatial information, as well as the management of relevant infrastructures in developing and developed contexts. Through the nine strategic pathways outlined, we can glean a way to deliver sustainable social, economic, and environmental development through the implementation of integrated geospatial information systems. The strategic pathways are underpinned by a series of principles for geospatial information that represent key characteristics and values: Strategic enablement; Transparent and accountable; Reliable, accessible and easily used; Collaboration and cooperation; Integrative solution; Sustainable and valued; Leadership and commitment. These principles promote consistent geospatial information management, resulting in more open, accountable responsive and efficient governing [3].

\subsection{A Roadmap for Building Land Resilience}

A Roadmap for improving land resilience within a country context has been developed. The roadmap utilizes a number of tools developed from the project Improving Resilience and Resilience Impact of National Land and Geospatial Systems [1] to assess the maturity of land and geospatial systems within a country context. The Roadmap is shown below, and is achieved through the implementation of the land resilience tools: 
- The Contextual Analysis Questionnaire is an operational tool used to assess the current status of land and geospatial systems within a country.

- The Pre and Post Disaster Recommendations for Land Resilience identifies key resilience indicators for land and geospatial organizations.

- The Land Resilience Maturity Index Assessment is a technical tool for quantifying the maturity of a country's land and geospatial systems in relation to land resilience.

- The Country Action Plan Template brings together the outputs of the three tools to delineate the dimensions to focus on for improving and enhancing the overall land resilience of a country.

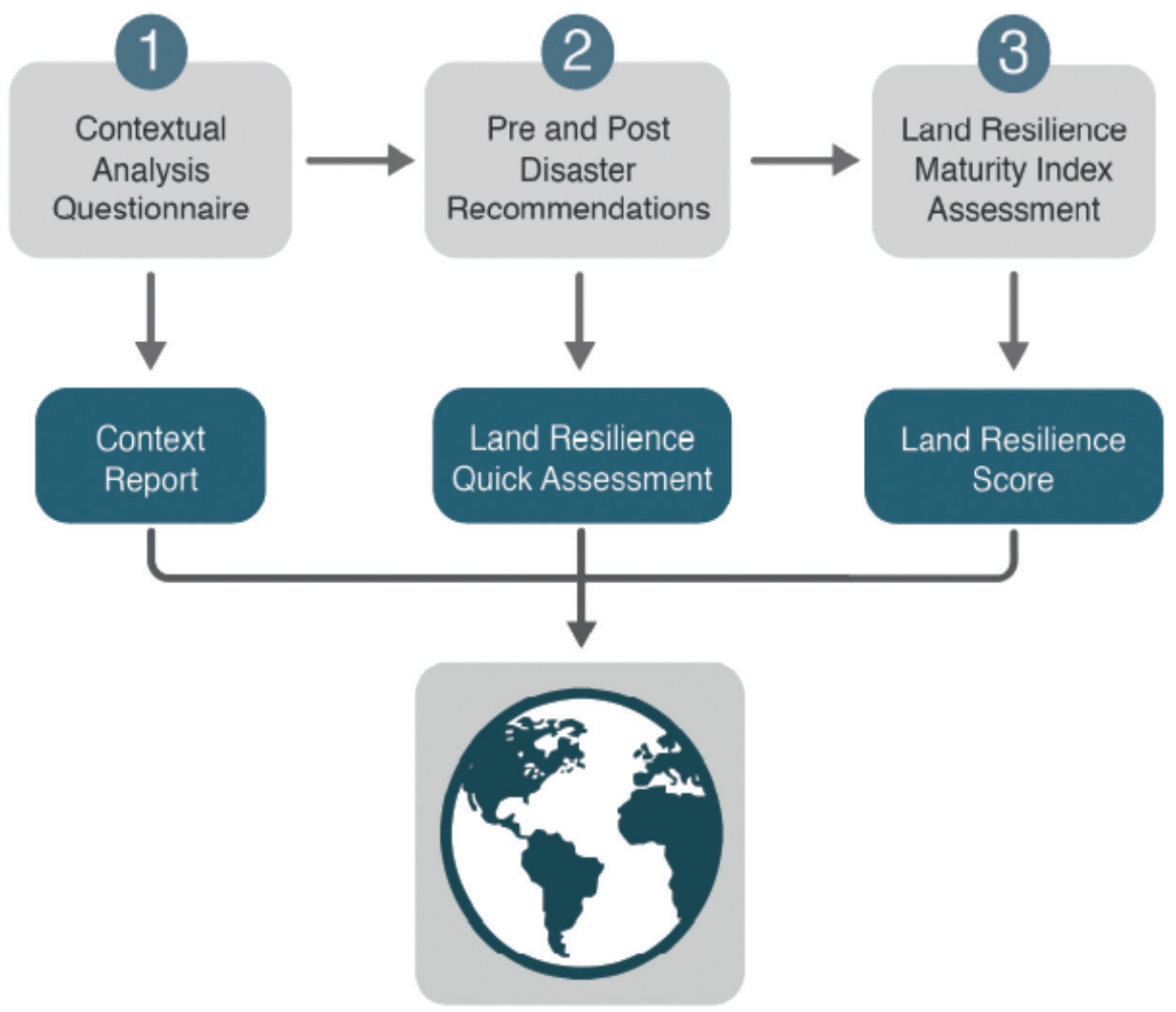

Country Action Plan

\section{FIGURE $\mathbf{5 . 3}$}

The Land Resilience Roadmap

The Roadmap facilitates the understanding of:

- how resilient land and geospatial systems are to disasters events 
- to what extent land and geospatial systems are able to contribute support to external applications such as disaster risk management activities

- areas that land and geospatial systems could improve or enhance to support disaster risk management functions

By following this Roadmap, the current level of maturity of the land administration systems, the comprehensiveness of geospatial systems, and the level of integration of these systems with disaster risk management activities within a specific country context can be determined which enables areas requiring attention to be identified and addressed, which is turns supports improvements to current practices and overall improved land resilience.

\subsection{Conclusion}

Improving land resilience starts with a desire from the community for a better approach to managing land. In the context of disasters, often specific events highlight the need for a change or outline situations where significant problems arise. This chapter highlights the importance of land and geospatial information in achieving land resilience and presents a way to understand the current arrangements of land and geospatial information to improve current practices.

Action is required though. Individuals and organizations much work to overcome sharing, integration and interoperability challenges, make better decisions, promote transparency and act cohesively to improve land resilience. In particular, the physical land and geospatial information itself. Though this information and systems may be vulnerable to a wide range of hazards and disaster events, there are many ways to enhance their resilience and significantly reduce any potential loss. Best practice guidelines along with suggestions offered in this chapter are key to securing the valuable land and geospatial information that upholds many other land resilience practices.

The rich land and geospatial resources give us better tools to anticipate, plan and respond to disaster related problems. But decision makers and stakeholders need to work hard to help to ensure that all of this information leads to effective action. This involves developing better integration strategies across organizations at all jurisdictional levels to ensure that information can be utilized for activities where it can benefit the larger community. It also means developing ways of encouraging participation in establishment and improvement in wider resilience activities. Finally, it means better tracking of outcomes to keep organizations and stakeholders accountable for their promised actions and so improvements can be observed and celebrated. 


\section{Bibliography}

[1] World Bank. Improving resilience and resilience impact of national land and geospatial systems, 2019.

[2] Internal Displacement Monitoring Centre. Global report on internal displacement, 2018.

[3] UN GGIM and World Bank. A strategic guide to develop and strengthen national geospatial information management, 2018.

[4] Francis Ghesquiere, Jan Kellett, Jack Campbell, Shyam Kc, and Robert Reid. The sendai report: managing disaster risks for a resilient future. Technical report, The World Bank, 2012.

[5] United Nations. Transforming our world: the 2030 agenda for sustainable development. United Nations General Assembly. Resolution 70/1, 2015.

[6] David Palmer. Security, risk and registration. Land use policy, 15(1):8394, 1998.

[7] UN-GGIM. The application of geospatial information - land administration and management, 2015.

[8] United Nations Human Settlements Programme (UN-HABITAT). Land and natural disasters: Guidance for practitioners, 2010.

[9] U UNISDR. Hyogo framework for action 2005-2015: Building the resilience of nations and communities to disasters. In Extract from the final report of the World Conference on Disaster Reduction (A/CONF. 206/6), volume 380. The United Nations International Strategy for Disaster Reduction Geneva, 2005. 